\title{
Tabetic arthropathy of the knee, complicated by lower limb myonecrosis
}

\author{
Jordan Sim $\odot 1$, 1,2 Yonghan Ting, ${ }^{1,2}$ Eugene Low ${ }^{1,2}$
}

${ }^{1}$ Tan Tock Seng Hospital, National Healthcare Group, Singapore

${ }^{2}$ Diagnostic Radiology, Tan Tock Seng Hospital, Singapore

\section{Correspondence to}

Dr Jordan Sim;

jordansim92@gmail.com

Accepted 30 June 2021

\section{DESCRIPTION}

A 52-year-old man presented with a 6-month history of lower limb swelling that has acutely worsened over the last month. He was diagnosed with syphilis more than 5 years ago. Plain radiograph of the knee done on presentation demonstrated deformity, debris, disorganisation and maintenance of bone density, consistent with neuropathic arthropathy (figure 1). MRI revealed loss of normal morphology of the muscles in the anterior compartment of the left shin, with areas of heterogeneous cystic change and lack of contrast enhancement (figures 2 and 3). These imaging findings are consistent with myonecrosis. The posterior compartment of the left calf was relatively spared.

Secondary infection of the necrotic muscles occurred and the patient had to undergo multiple sessions of debridement, which nonetheless failed to clear the necrotic/infective tissues. Tissue cultures grew methicillin-susceptible Staphylococcus aureus and Pseudomonas aeruginosa. He eventually underwent an above-knee amputation (AKA) for infection source control. The team chose to proceed with an AKA instead of a below-knee amputation as the soft tissues below the knee were deemed too unhealthy for proper wound coverage and also to optimise prosthesis function postoperatively.

Syphilis is caused by infection with Treponema pallidum, a spirochete bacterium that is usually sexually transmitted. Syphilis has re-emerged in several regions including North America, Europe and China, largely due to host-associated factors such as high-risk sexual activity, migration and travel. $^{1}{ }^{2}$ While early, uncomplicated syphilis is easily treatable with a single intramuscular injection of benzathine penicillin G; treatment might

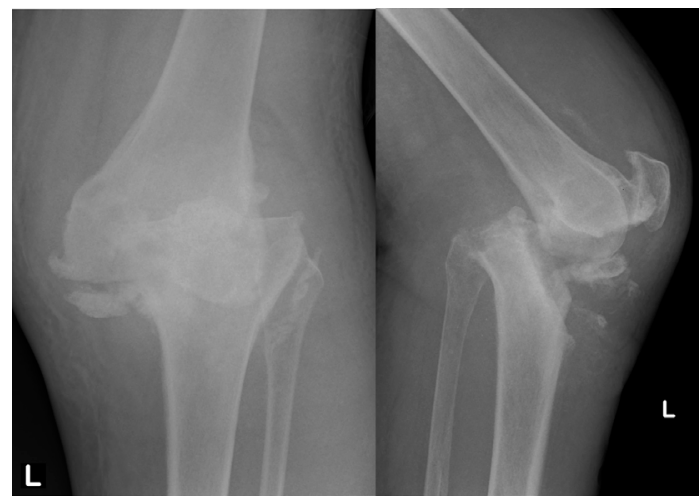

Figure 1 Anterior-posterior and lateral knee radiograph of the patient shows destruction and disorganisation with anterior dislocation of the distal femur.

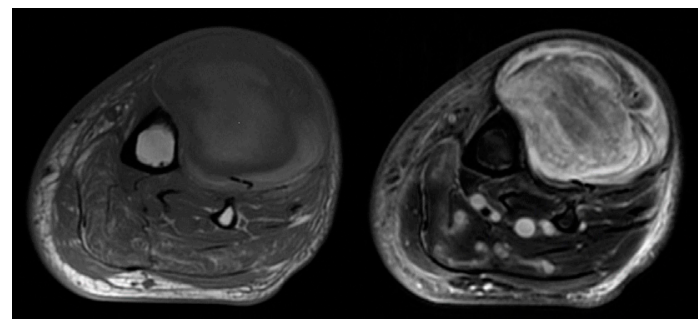

Figure 2 Precontrast axial T1 and T2 images demonstrate loss of normal muscle morphology with heterogeneous cystic change in the anterior compartment of the left lower leg.

not undo any irreversible damage the infection has already done to the cardiovascular and nervous system. Tabes dorsalis is a manifestation of late tertiary neurosyphilis, seen in 2\%-9\% of patients in untreated syphilis. Tabetic arthropathy occurs in $6 \%-10 \%$ of these patients. ${ }^{3}$ Tabetic arthropathy can present up to 30 years after the primary syphilis infection.

Most cases of tabetic arthropathy are diagnosed on the basis of radiological findings with positive serological and/or spinal fluid results. ${ }^{4}$ The destructive process of the bone and joint is believed to be due to the absence of normal protective sensory feedback. This predisposes the patient to repetitive trauma and injury, causing progressive joint destruction. The radiographical features of a Charcot joint have traditionally been described as six 'D's, namely, density (osteopenia or sclerosis),

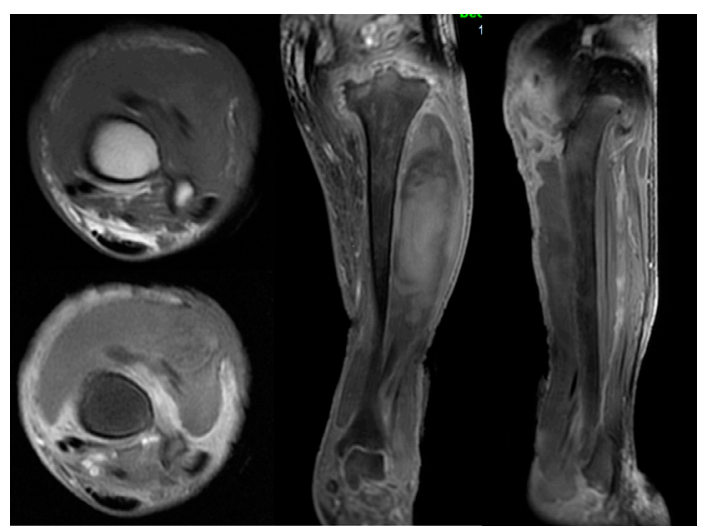

Figure 3 Top left: precontrast axial T1. The rest of the images are postcontrast $\mathrm{T} 1$ sequences: axial, coronal and sagittal. There is lack of contrast enhancement in the anterior compartment of the left lower leg; these, along with the observations in figure 2, are findings in keeping with myonecrosis, which was subsequently proven intraoperatively. 
destruction (osseous fragmentation and resorption), debris, distension (joint effusion), disorganisation and dislocation. The severity of the radiographical features are often out of proportion to the symptoms that the patients experience.

Myonecrosis is a rare entity most commonly seen as sequelae of trauma or long-standing diabetes. ${ }^{56}$ The pathogenesis of myonecrosis is poorly understood; the prevailing theory is that tissue ischaemia triggers an inflammatory cascade leading to ischaemic necrosis. In patients with diabetes, vasculopathic changes further accelerate this process. ${ }^{7}$ Radiologically, findings of myonecrosis are non-specific, most frequently seen as T1 isointense with T2 prolongation and decreased contrast enhancement. Although it is difficult to pinpoint the cause of myonecrosis in this patient, it is possible that the muscles in the patient's left lower leg were put under chronic stress and repeated microtrauma, thus resulting in myonecrosis.

The imaging features of tabetic arthropathy and myonecrosis have been described separately in previous publications ${ }^{489}$; our

\section{Learning points}

Syphilis is not a disease from a bygone era and tabes dorsalis should be in the list of differential diagnoses in patients with neuropathic arthropathy.

- Neuroarthropathy can often be confidently diagnosed on plain radiographs using the six 'D's.

- It is important to recognise the imaging features of myonecrosis as opposed to more common conditions such as myositis and abscesses. literature review reveals that this is the first report of tabetic arthropathy of the knee complicated by myonecrosis.

Contributors JS drafted and revised the paper. YT and EL provided guidance and revised the draft paper.

Funding The authors have not declared a specific grant for this research from any funding agency in the public, commercial or not-for-profit sectors.

Competing interests None declared.

Patient consent for publication Obtained.

Provenance and peer review Not commissioned; externally peer reviewed.

ORCID iD

Jordan Sim http://orcid.org/0000-0002-4164-1643

\section{REFERENCES}

1 Stamm LV. Syphilis: re-emergence of an old foe. Microb Cell 2016;3:363-70

2 Simms I, Fenton KA, Ashton M, et al. The re-emergence of syphilis in the United Kingdom: the new epidemic phases. Sex Transm Dis 2005;32:220-6.

3 Gupta R. A short history of neuropathic arthropathy. Clin Orthop Relat Res 1993:43???49.

4 Allali F, Rahmouni R, Hajjaj-Hassouni N. Tabetic arthropathy. A report of 43 cases. Clin Rheumatol 2006:25:858-60.

5 Lawrence L, Tovar-Camargo O, Lansang MC, et al. Diabetic myonecrosis: a diagnostic and treatment challenge in longstanding diabetes. Case Rep Endocrinol 2018;2018:1-4

6 Angelini A, Mavrogenis AF, Pagliarini E, et al. Calcific myonecrosis of the leg: a rare entity. Medicina 2019;55:542.

7 Horton WB, Taylor JS, Ragland TJ, et al. Diabetic muscle infarction: a systematic review. BMJ Open Diabetes Res Care 2015;3:e000082-8.

8 Cunningham J, Sharma R, Kirzner A, et al. Acute myonecrosis on MRI: etiologies in an oncological cohort and assessment of interobserver variability. Skeletal Radiol 2016;45:1069-78.

9 En-Nafaa I, Ziadi T, Africha T. Tabetic arthropathy of the knee: MRI aspects. Joint Bone Spine 2016;83:579.

Copyright 2021 BMJ Publishing Group. All rights reserved. For permission to reuse any of this content visit

https://www.bmj.com/company/products-services/rights-and-licensing/permissions/

BMJ Case Report Fellows may re-use this article for personal use and teaching without any further permission.

Become a Fellow of BMJ Case Reports today and you can:

- Submit as many cases as you like

- Enjoy fast sympathetic peer review and rapid publication of accepted articles

- Access all the published articles

- Re-use any of the published material for personal use and teaching without further permission

Customer Service

If you have any further queries about your subscription, please contact our customer services team on +44 (0) 2071111105 or via email at support@bmj.com.

Visit casereports.bmj.com for more articles like this and to become a Fellow 